\title{
Erosividade da chuva em municípios do Mato Grosso: Distribuição sazonal e correlações com dados pluviométricos ${ }^{1}$
}

\author{
Cristiana 0. S. Almeida ${ }^{2}$, Ricardo S. S. Amorim ${ }^{3}$, Flávio L. F. Eltz ${ }^{4}$, \\ Eduardo G. Couto ${ }^{3} \&$ Sara A. Jordani ${ }^{5}$
}

\begin{abstract}
RESU MO
A erosividade das chuvas constitui um fator imprescindível para predição das perdas de solo por erosão hídrica. D esta forma, o presente trabalho foi desenvolvido com os seguintes objetivos: modelar a relação entre os valores do índice de erosividade da chuva $\left(\mathrm{El}_{30}\right.$ ) mensal obtidos a partir de dados pluviográficos com a precipitação e coeficientes de chuva mensal para quatro municípios (Canarana, São José do Rio Claro, Poxoréo e Vera) do Estado de M ato Grosso; determinar o fator de erosividade (R) a partir de dados pluviométricos para esses quatro municípios, bem como o seu período de retorno e sua probabilidade de ocorrência; e estudar a distribuição anual, sazonal e mensal do $\mathrm{El}_{30}$ nestes quatro municípios. A relação potencial entre o índice de erosividade da chuva e o coeficiente de chuva possibilita estimar a erosividade da chuva mensal e anual com boa confiabilidade (ERM $\leq 7 \%$ ) para os municípios de Canarana, Vera e São José do Rio Claro. Entretanto, para Poxoréo esta boa confiabilidade só ocorre para a erosividade anual. Nos quatro municípios, as estações primavera e verão correspondem ao período do ano de maior erosividade, sendo responsável, a exceção de Poxoréo, por uma proporção maior ou igual a $94 \%$ do valor da erosividade total anual.
\end{abstract}

Palavras-chave: erosão hídrica, dados pluviográficos, coeficiente da chuva

\section{Rainfall erosivity in municipal districts of Mato Grosso: Seasonal distribution and correlation with rainfall data}

\begin{abstract}
The rainfall erosivity constitutes an indispensable factor for prediction of soil losses by water erosion. In this way, the present study was carried out with the objectives to model the relationship among the erosivity index $\left(\mathrm{El}_{30}\right)$ monthly values, obtained from rainfall chart data with the precipitation and monthly rainfall coefficient for four municipal districts (Canarana, São José of Rio Claro, Poxoréo and Vera) of $M$ ato $G$ rosso State; to determine the erosivity factor $(R)$ obtained from rainfall data for the four municipalities, as well as its return period and its occurrence probability; and to study the $\mathrm{El}_{30}$ annual, seasonal and monthly distribution in these four municipalities. The potential relationship between the rainfall erosivity index and the rainfall coefficient make possible to evaluate the monthly and annual rainfall erosivity with good reliability (ERM $\leq 7 \%$ ) for the municipalities of Canarana, Vera and São José of Rio Claro. How ever, for Poxoréo this good reliability is verified only for the annual erosivity. In the four municipalities the spring and summer seasons correspond to the period of larger erosivity, being responsible, except for Poxoréo, for $94 \%$ or more of the annual total erosivity.
\end{abstract}

Key words: water erosion, rainfall data, rainfall coefficient

\footnotetext{
1 Parte da Dissertação do primeiro autor, apresentada ao Programa de Pós-Graduação em Agronomia da FAV/UnB, Brasília, DF 2 Engenheira Agrônoma, IN CRA, SIG quadra 04 lote 417/550 CEP 70710-400, Brasília, DF. Fone: (61) 3342-2993. E-mail: kika.df@gmail.com ${ }^{3}$ DSER/U FMT. Av. Fernando Correa da Costa s/n, Campus U FMT. CEP 78060-900 Cuiabá, MT. Fone/Fax: (65) 3615 8616/8668. E-mail: rsamorim@ufmt.br; couto@cpd.ufmt.br

${ }^{4}$ DS/UFSM. Bolsista do CN Pq. Avenida Roraima, n. 1000, Cidade Universitária, Bairro Camobi, CEP 97105-900 Santa Maria, RS. E-mail: flavioeltz@gmail.com

${ }^{5}$ Engenharia Florestal da UFMT. E-mail: pequenasara@hotmail.com
} 


\section{INTRODUÇÃO}

A erosão hídrica do solo é um dos grandes problemas da agricultura do Estado de Mato Grosso e do Brasil, causando redução nos rendimentos das culturas e grandes danos ao solo, como perdas de matéria orgânica e nutrientes, e ao ambiente como assoreamento, eutrofização e poluição das fontes de água superficiais (Peñalva Bazzano, 2005).

As perdas de solo que ocorrem por erosão hídrica são provocadas pelo impacto direto das gotas da chuva e/ou pelo escoamento superficial do excesso de água da chuva, conhecida como en xurrada. A erosão hídrica é a consequência da interação da chuva com o solo, isto é, a resultante do poder da chuva em causar erosão e da capacidade do solo em resistir à erosão (Peñalva Bazzano, 2005).

Um estudo desenvolvido pelo ISRIC/UNEP, do qual participou a Embrapa Solos, indicou que 15\% das terras já foram severamente degradados e 70\% deste total correspondem às perdas da camada superficial do solo por erosão hídrica, motivo pelo qual este processo é considerado uma das principais causas da redução da capacidade produtivas dos solos (Hernani et al., 2002).

As regiões dos municípios de Canarana, Vera, Poxoréo e São José do Rio Claro apresentam intensa degradação dos solos pela erosão hídrica a qual tem, como uma das principais causas, o efeito impactante das atividades antrópicas realizadas nas últimas décadas nessas regiões incluindo, dentre elas, o desmatamento da floresta nativa,o uso intensivo e o manejo inadequado do solo, desrespeitando totalmente a capacidade de uso dos solos da região (Almeida, 2009).

Segundo Amorim et al. (2010), diversos modelos matemáticos vêm sendo desenvolvidos e aperfeiçoados desde a década de 50 , com o intuito de prever a magnitude das perdas de solo por erosão, visando implementar ferramentas que possibilitam avaliar as perdas de solo com o propósito de auxiliar no planejamento agrícola. O modelo USLE (Universal Soil Loss Equation) é um dos modelos mais utilizados no mundo, podendo ser utilizado em escala universal, caso que depende de dados locais específicos (Bertoni et al., 1975). Dentre os fatores inclusos no modelo USLE, se destaca o fator erosividade da chuva (R) que, segundo Wischmeier \& Smith (1978), é um índice numérico que expressa a capacidade da chuva esperada em dada localidade, de causar erosão em uma área sem proteção.

A determinação do valor médio da erosividade das chuvas através de registros pluviométricos e/ou pluviográficos diários de vários anos e cálculos computacionais, permite estudar o impacto ambiental de determinadas práticas agrícolas, desenvolver pesquisas em erosão e planejar ações de conservação do solo, além de obras de engenharia civil, como pontes e represas, entre outras (Peñalva Bazzano, 2005).

No Brasil, o parâmetro $\mathrm{EI}_{30}$ tem sido amplamente estudado e utilizado; no entanto, no Estado de Mato Grosso apenas dois trabalhos para obtenção deste índice foram publicados até o presente momento, sendo um na década de 90, por Morais et al. (1991); os autores determinaram os índices $\mathrm{EI}_{30}$ médios anuais referentes às estações de Barranquinho e Flechas, do município de Cáceres, sudoeste do Mato Grosso que foram, respectivamente, de 8.493 e $7.830 \mathrm{MJ} \mathrm{mm} \mathrm{ha}^{-1} \mathrm{~h}^{-1} \mathrm{ano}^{-1}$ e o outro, mais recente, por Almeida et al. (2011), que obtiveram valor médio de $\mathrm{R}$ para uma série de dados de 19 anos, igual a 8.810 $\mathrm{MJ} \mathrm{mm} \mathrm{ha}^{-1} \mathrm{~h}^{-1}$ ano $^{-1}$ no município de Cuiabá, MT, sendo que este valor médio possui probabilidade de ocorrência de $42,92 \%$ e período de retorno de 2,33 anos.

Em conjunto com novos trabalhos em desenvolvimento por pesquisadores nacionais, esses resultados representam um valioso banco de dados para locação das linhas iso-erosivas do Brasil. Apesar disto e em função da carência de dados meteorológicos, sendo ainda mais crítica quando se trata de dados pluviográficos, poucos trabalhos de determinação da erosividade da chuva têm sidos desenvolvidos no Estado do Mato Grosso. Desta forma, torna-se fundamental o ajuste de uma metodologia que permita estimar a erosividade da chuva a partir de dados pluviométricos, mais disponíveis neste estado contornando, assim, a carência das estações pluviográficas e possibilitando a obtenção de dados de erosividade mais representativos.

Neste contexto se objetivou, com o presente trabalho: a) descrever matematicamente a relação entre os valores de $\mathrm{EI}_{30}$ mensal obtidos a partir de dados pluviográficos com a precipitação e coeficientes de chuva mensal para quatro municípios (Canarana, São José do Rio Claro, Poxoréo e Vera) do Estado de Mato Grosso; b) determinar o fator de erosividade (R) a partir de dados pluviométricos para esses municípios, tal como seu período de retorno e a probabilidade de ocorrência e c) estudar a distribuição anual, sazonal e mensal do índice de erosividade $\left(\mathrm{EI}_{30}\right)$ desses quatro municípios.

\section{Material e MÉTODOS}

Para o desenvolvimento do presente trabalho foram utilizados dados pluviográficos e pluviométricos obtidos junto ao $9^{\circ}$ Distrito de Meteorologia do Instituto Nacional de Meteorologia (INMET) e Agência Nacional das Águas (ANA) das estações localizadas em quatro municípios (Canarana, Vera, Poxoréo e São José do Rio Claro) do Estado de Mato Grosso.

Nas regiões dos municípios estudados predomina o tipo climático Tropical Quente Sub-úmido (Awi), de acordo com a classificação climática de Köeppen, com predomínio de duas estações bem definidas quanto à umidade, sendo uma chuvosa (outubro a março) e outra seca (abril a setembro), com precipitação anual variando entre 1000 a $1800 \mathrm{~mm}$.

Na Tabela 1 são apresentados os dados das estações estudadas no presente trabalho, tais como latitude, longitude, altitude, número de chuvas erosivas, série de dados pluviográficos e pluviométricos da estações em estudo.

Obtiveram-se as chuvas erosivas em pluviograma no qual são registrados a lâmina de chuva e o tempo de ocorrência; com amplitude de registro variando de zero a $10 \mathrm{~mm}$ de precipitação, com unidade de $0,1 \mathrm{~mm}$ durante $24 \mathrm{~h}$, com sifonamento a cada $10 \mathrm{~mm}$.

Considerou-se chuva individual aquelas separadas da anterior e da posterior, por um período de no mínimo seis horas com chuvas de no máximo $1,0 \mathrm{~mm}$ e chuvas erosivas aquelas com quantidade igual ou superior a $10,0 \mathrm{~mm}$ ou igual ou superior 
Tabela 1. Informações de latitude, longitude, altitude, número de chuvas erosivas, períodos de dados pluviográficos e pluviométricos das estações meteorológicas utilizadas no presente estudo

\begin{tabular}{|c|c|c|c|c|}
\hline Informações & Canarana & Vera & Poxoréo & São J osé do Rio Claro \\
\hline Latitude & $13^{\circ} 28^{\prime} 12^{\prime \prime}$ & $12^{\circ} 17^{\prime} 24^{\prime \prime}$ & $15050^{\prime} 48^{\prime \prime}$ & $13^{\circ} 26^{\prime} 48^{\prime \prime}$ \\
\hline Longitude & $52^{\circ} 16^{\prime} 12^{\prime \prime}$ & $55^{\circ} 17^{\prime} 24^{\prime \prime}$ & $54023^{\prime} 48^{\prime \prime}$ & $56043^{\prime} 12^{\prime \prime}$ \\
\hline Altitude & $430 \mathrm{~m}$ & $415 \mathrm{~m}$ & $450 \mathrm{~m}$ & $350 \mathrm{~m}$ \\
\hline Série de dados pluviográficos & 1991, 1992 e 1995 & 1997, 1999, 2003 e 2005 & 1991 a 1994, 2003 e 2005 & 1991 a 1994 \\
\hline Série de dados pluviométricos & 1986 a 2009 & 1975 a 2007 & 1977 a 2007 & 1991 a 2007 \\
\hline Número de chuvas erosivas & 87 & 196 & 192 & 156 \\
\hline
\end{tabular}

a 6,0 mm, desde que ocorridas em menos de 15 min, segundo os critérios propostos por Wischmeier \& Smith (1978), com modificações sugeridas por Carvalho et al. (1989).

A erosividade mensal, anual e média das chuvas foi expressa pelo índice $\mathrm{EI}_{30}$ (Wischmeier \& Smith, 1958) no Sistema Internacional de Unidades - MJ mm ha ${ }^{-1} \mathrm{~h}^{-1}$ (Foster et al., 1981), obtida pelo produto entre a energia cinética total da chuva (EC - MJ ha $\left.{ }^{-1}\right)$ e a intensidade máxima em $30 \mathrm{~min}\left(\mathrm{I}_{30}-\mathrm{mm} \mathrm{h}^{-1}\right)$, de acordo com Wischmeier \& Smith (1958) além de agrupadas durante meses e anos. A energia cinética das chuvas foi determinada através da Eq. 1 Wischmeier \& Smith (1958), ajustada ao Sistema Internacional de Unidades por Foster et al. (1981).

$$
\mathrm{EC}=0,119+0,0873 \times \log \mathrm{Ip}
$$

em que:

$$
\begin{aligned}
& \mathrm{BC} \text { - é a energia cinética, } \mathrm{MJ} \mathrm{ha}^{-1} \mathrm{~mm}^{-1} \\
& \mathrm{Ip} \text { - é a intensidade de precipitação da chuva, } \mathrm{mm} \mathrm{h}^{-1}
\end{aligned}
$$

Segundo Foster et al. (1981), o diâmetro das gotas de chuva não aumenta quando as intensidades são iguais ou superiores a $76 \mathrm{~mm} \mathrm{~h}^{-1}$; desta forma, para essas condições de intensidade de precipitação a energia cinética passa a ter valor máximo de $0,283 \mathrm{MJ} \mathrm{ha}^{-1} \mathrm{~mm}^{-1}$. A energia cinética acumulada de cada segmento de $10 \mathrm{~min}$ de uma chuva erosiva individual foi obtida pela aplicação da Eq. 2.

$$
\mathrm{EC}_{\mathrm{s}}=\mathrm{EC} \times \mathrm{h}
$$

em que:

$\mathrm{EC}$ - é a energia cinética no segmento de chuva, $\mathrm{MJ} \mathrm{ha}^{-1}$

$\mathrm{h}$ - é a quantidade de chuva no segmento uniforme, $\mathrm{mm}$

Obteve-se a energia cinética total da chuva erosiva individual pelo somatório da energia cinética de cada segmento da chuva enquanto a intensidade máxima em trinta minutos foi obtida conforme a Eq. 3 proposta por Carvalho et al. (1989):

$$
I_{30}=\frac{\left(\sum_{i=1}^{n} i_{n i} \times t_{n i}\right)}{30}
$$

em que:

$\mathrm{I}_{30}$ - é a intensidade da chuva em $30 \mathrm{~min}$ consecutivos, $\mathrm{mm} \mathrm{h}^{-1}$ $i_{n}$ - é o valor da intensidade da chuva de ordem $\mathrm{n}\left(\mathrm{mm} \mathrm{h}^{-1}\right)$, ocorrida dentro do período de $30 \mathrm{~min}$

$\mathrm{t}_{\mathrm{n}}$ - é o tempo de ocorrência da intensidade da chuva de ordem n, ocorrida dentro do período de $30 \mathrm{~min}$ Eq. 4:

O índice de erosividade $\left(\mathrm{EI}_{30}\right)$ de cada chuva foi obtido pela

$$
\mathrm{EI}_{30}=\mathrm{EC}_{\mathrm{t}} \times \mathrm{I}_{30}
$$

em que:

$\mathrm{EI}_{30}$ - é o índice de erosividade da chuva erosiva individual, MJ mm ha ${ }^{-1} h^{-1}$

$\mathrm{I}_{30}$ - é a intensidade máxima da chuva no período de 30 minutos consecutivos, $\mathrm{mm} \mathrm{h}^{-1}$

Por sua vez, o $\mathrm{EI}_{30}$ mensal foi obtido pelo somatório do $\mathrm{EI}_{30}$ de cada chuva erosiva ocorrida no mês e o $\mathrm{EI}_{30}$ anual pelo somatório do $\mathrm{EI}_{30}$ de cada mês, cujo fator $\mathrm{R}$ foi representado pela média dos valores de $\mathrm{EI}_{30}$ anuais.

O coeficiente de chuva para cada mês do ano foi calculado com base na Eq. 5 proposta por Lombardi Neto (1977) utilizandose as séries de dados pluviométricos de cada localidade estudada.

$$
\mathrm{R}_{\mathrm{c}}=\mathrm{Pm}^{2} / \mathrm{Pa}
$$

em que:

$$
\begin{aligned}
& \mathrm{Rc} \text { - é o coeficiente de chuva, } \mathrm{mm} \\
& \mathrm{Pm} \text { - é a precipitação média mensal, } \mathrm{mm} \\
& \mathrm{Pa} \text { - é a precipitação média anual, } \mathrm{mm}
\end{aligned}
$$

Através do programa estatístico SPSS 15.0 procedeu-se à análise de regressão entre os dados de índices de erosividade médios mensais com o coeficiente de chuva e precipitação mensais, para os seguintes modelos: linear, potencial, exponencial, quadrática e logarítmica sendo apresentados, desta forma, os coeficientes de ajuste para o modelo matemático que apresentou, na análise de variância, significância para regressão, para os parâmetros do modelo e maior coeficiente de determinação $\left(\mathrm{R}^{2}\right)$.

Nas análises de probabilidade de ocorrência e do período de retorno do índice $\mathrm{EI}_{30}$ determinados para os anos em estudo, foram utilizadas a lei de probabilidade logarítmica e a teoria de valores extremos preconizadas por Schwab et al. (1981). O período de retorno e a probabilidade de ocorrência foram obtidos pelas Eqs. 6 e 7, respectivamente. 


$$
\begin{gathered}
\mathrm{TR}=\frac{(\mathrm{N}+1)}{\mathrm{m}} \\
\operatorname{Pr}=\frac{100}{\mathrm{TR}}
\end{gathered}
$$

em que:

TR - é o período de retorno no qual o índice de erosividade é igualado ou superado

$\mathrm{N}$ - é o número de anos de registro de dados (tamanho da série)

m - é o número de ordem do índice de erosividade quando a série de dados de erosividade é colocada em ordem decrescente de magnitude

Pr - é a probabilidade de ocorrência

Em seguida, ajustou-se o modelo de distribuição de probabilidades de Gumbel para o cálculo anual das erosividades máximas, por meio das Eqs. 8, 9 e 10, conforme Pinto et al. (1996):

$$
\begin{gathered}
\mathrm{Y}_{\mathrm{TR}}=-\ln \left[-\ln \left(1-\frac{1}{\mathrm{TR}}\right)\right] \\
\mathrm{K}_{\mathrm{TR}}=-0,45+0,78 \times \mathrm{Y}_{\mathrm{TR}} \\
\mathrm{X}_{\mathrm{TR}}=\overline{\mathrm{X}}+\mathrm{S} \times \mathrm{K}_{\mathrm{TR}}
\end{gathered}
$$

em que:

$\mathrm{Y}_{\mathrm{TR}}$ - é a variável reduzida da distribuição de Gumbel

TR - é o período de retorno, anos

$\mathrm{X}_{\mathrm{TR}}$ - é a erosividade máxima (anual ou mensal) para determinado TR, MJ mm ha ${ }^{-1} \mathrm{~h}^{-1}$ ano ${ }^{-1}$

$\mathrm{K}_{\mathrm{TR}}$ - é o fator de frequência, adimensional

$\mathrm{X}$ - é a média da erosividade máxima anual ou mensal, $\mathrm{MJ}$ $\mathrm{mm} \mathrm{ha}^{-1} \mathrm{~h}^{-1}$ ano $^{-1}$

S - é o desvio padrão dos dados de erosividade máxima, MJ mm ha ${ }^{-1} \mathrm{~h}^{-1}$ ano $^{-1}$

A Eq. 8 é chamada Modelo Geral de Ven Te Chow. Essas equações permitem o emprego de uma população de dados e não apenas de uma amostra simplificando, com isto, as equações da distribuição de Gumbel.

Utilizou-se o teste de Kolmogorov-Smirnov com o objetivo de verificar a adequabilidade à distribuição de Gumbel para a representação probabilística dos dados.

Foi utilizado papel de probabilidade logarítmica para plotar os valores dos índices de erosividade observados, em que os valores dos índices anuais de erosividade, para qualquer período de retorno desejado, ou vice-versa, podem ser facilmente obtidos pela leitura direta na curva de distribuição de probabilidade ou calculados pela aplicação da equação dos valores teóricos.

\section{RESULTADOS E DISCUSSÃO}

Na Tabela 2 se acham os parâmetros estatísticos (média, desvio padrão, erro padrão médio, coeficientes de variação e coeficientes de correlação) dos valores mensais e anuais do índice de erosividade da chuva, da precipitação e do coeficiente de chuva, obtidos a partir da análise da série de dados pluviográficos dos municípios de Canarana, Vera, Poxoréo e São José de Rio Claro, no Estado de Mato Grosso.

O pequeno tamanho e a alta descontinuidade das séries de dados pluviográficos dificultam a caracterização do Fator $\mathrm{R}$ para as localidades em estudo, uma vez que não serão capazes de representar as variações cíclicas comuns aos parâmetros climáticos, as quais se efletem na grande variabilidade temporal das chuvas e de sua erosividade. Segundo Wischmeier \& Smith (1978), são necessários pelo menos 20 anos de informações para se ter um valor de erosividade da chuva representativo de uma; entretanto e em função da escassez de informações de estações pluviográficas no Brasil, vários pesquisadores vêm utilizando correlações entre a erosividade, determinadas em registros pluviográficos detalhados, para determinar a erosividade por meio de séries pluviométricas históricas para diversas regiões (Silva, 2004; Gonçalves et al., 2006; Mello et al., 2007; Montebeller et al., 2007; Men et al., 2008; Almeida, 2009; Silva et al., 2010; Arai et al., 2010). Desta forma, no presente trabalho os dados pluviográficos serão utilizados para estabelecer e descrever matematicamente a relação entre o índice de erosividade da chuva $\left(\mathrm{EI}_{30}\right)$ e dados pluviométicos (precipitação e coeficiente de chuva) mensais.

De maneira geral, os índices de erosividade da chuva mensais $\left(\mathrm{EI}_{30 \mathrm{~m}}\right)$ apresentaram coeficientes de correlação significativos $(\mathrm{p} \leq 0,01)$ com os dados de precipitação mensal $\left(\mathrm{PPT}_{\mathrm{m}}\right)$ e com o coeficiente de chuva mensal $\left(\mathrm{Rc}_{\mathrm{m}}\right)$, sobremaneira no período de maior ocorrência das chuvas (outubro a março), sendo que os valores de r para este período, com exceção do município de Poxoréo e dos meses de dezembro e março para os municípios de Canarana e Vera, respectivamente, foram superiores a 0,65, tanto para precipitação mensal quanto para coeficiente de chuva mensal (Tabela 2). Dentre as localidades estudadas o município de Poxoréo foi o que apresentou menores valores de correlação; apesar disto todas foram significativas a nível de $1 \%$ de probabilidade.

Considerando as limitações das séries de dados pluviográficos das localidades em estudo listadas anteriormente, a disponibilidade de dados pluviométricos com séries maiores e sem descontinuidade e a existência de correlação significativa do $\mathrm{EI}_{30 \mathrm{~m}}$ com a PPT $\mathrm{m}$ e $\mathrm{Rc}_{\mathrm{m}}$, foi possível ajustar equações de regressão para descrever, matematicamente, a relação do $\mathrm{EI}_{30 \mathrm{~m}}$ com a $\mathrm{PPT}_{\mathrm{m}} \mathrm{e} \mathrm{Rc}_{\mathrm{m}}$, e então se poder estimar o $\mathrm{EI}_{30}$ a partir dos dados pluviométricos. Desta análise de regressão a melhor relação entre os referidos parâmetros, para todas as localidades, foi a potencial, expressa pelas Eqs. 11, 12, 13 e 14 para os municípios de Canarana, Vera, Poxoréo e São José do Rio Claro, respectivamente. São apresentadas aqui apenas as equações que têm, como variável preditora, o coeficiente de chuva mensal devido aos seus melhores ajustes, comparativamente quando se utilizou a variável $\mathrm{PPT}_{\mathrm{m}}$ como preditora. 
Tabela 2. Parâmetros estatísticos (média, erro padrão médio, coeficiente de variação e coeficiente de correlação) mensal e anual da precipitação (PPT, mm), do índice de erosividade da chuva (El $\left.{ }_{30}, \mathrm{MJ} \mathrm{mm}(\mathrm{ha} \mathrm{h})^{-1}\right)$, do coeficiente de chuva (Rc) baseados nas séries de dados pluviográficos dos municípios estudados

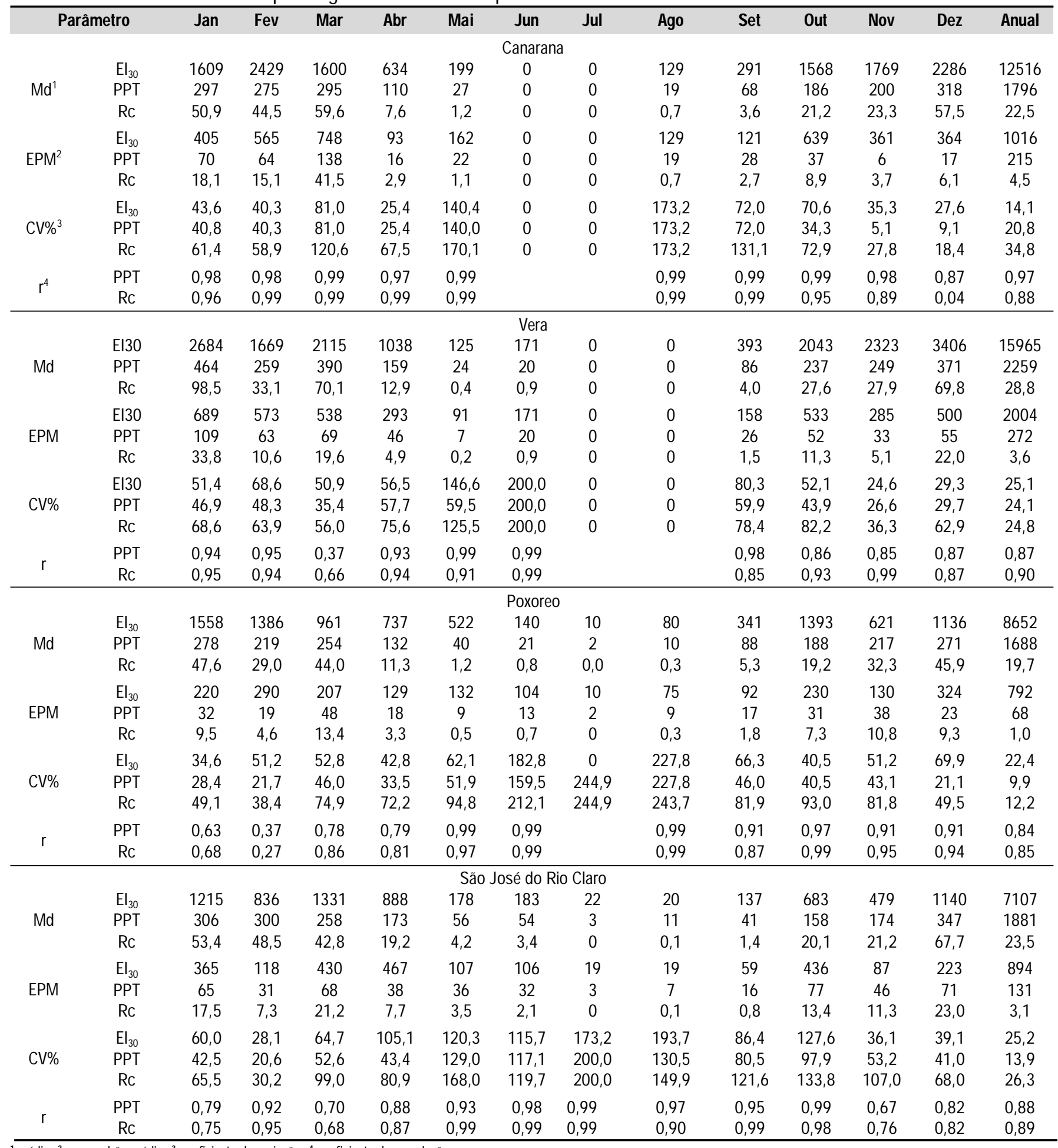

${ }^{1}$ média; ${ }^{2}$ erro padrão médio; ${ }^{3}$ coeficiente de variaçãao; ${ }^{4}$ coeficiente de correlaçãa

$$
\begin{array}{ll}
\mathrm{EI}_{30 \mathrm{~m}}=317,397829 \times \mathrm{Rc}_{\mathrm{m}}{ }^{0,484654} & \mathrm{R}^{2}=0,86 \\
\mathrm{EI}_{30 \mathrm{~m}}=399,538719 \times \mathrm{Rc}_{\mathrm{m}}{ }^{0,458718} & \mathrm{R}^{2}=0,84 \\
\mathrm{EI}_{30 \mathrm{~m}}=272,865645 \times \mathrm{Rc}_{\mathrm{m}}{ }^{0,419164} & \mathrm{R}^{2}=0,66
\end{array}
$$$$
\mathrm{EI}_{30 \mathrm{~m}}=147,262400 \times \mathrm{Rc}_{\mathrm{m}}^{0,533025}
$$$$
\mathrm{R}^{2}=0,83
$$

O melhor ajuste do modelo potencial para estimar o índice de erosividade da chuva a partir de dados pluviométricos também foi observado para outras localidades, dentre as quais as de Campinas, SP (Lombardi Neto, 1977), Santa Rosa, RS 
Tabela 3. Índices de erosividade da chuva mensais $\left(\mathrm{El}_{30 \mathrm{~m}}\right)$ e anuais $\left(\mathrm{El}_{30 \mathrm{a}}\right)$ obtidos a partir da análise de pluviogramas, estimados pela equações e os respectivos erros relativos das estimativas anuais e mensais para os municípios de Canarana, Vera, Poxoréo e São José do Rio Claro

\begin{tabular}{|c|c|c|c|c|c|c|c|c|c|c|c|c|c|c|c|c|}
\hline \multirow{3}{*}{ Mês } & \multicolumn{4}{|c|}{ Canarana } & \multicolumn{4}{|c|}{ Vera } & \multicolumn{4}{|c|}{ Poxoréo } & \multicolumn{4}{|c|}{ São J osé do Rio Claro } \\
\hline & \multicolumn{2}{|c|}{$\mathrm{El}_{30}{ }^{1}$} & \multirow{2}{*}{$\mathrm{ER}^{4}$} & \multirow{2}{*}{ ERM $^{5}$} & \multicolumn{2}{|c|}{$\mathrm{El}_{30}$} & \multirow{2}{*}{ ER } & \multirow{2}{*}{ ERM } & \multicolumn{2}{|c|}{$\mathrm{El}_{30}$} & \multirow{2}{*}{ ER } & \multirow{2}{*}{ ERM } & \multicolumn{2}{|c|}{$\mathrm{El}_{30}$} & \multirow{2}{*}{ ER } & \multirow{2}{*}{ ERM } \\
\hline & $\mathrm{AP}^{2}$ & $\mathrm{EST}^{3}$ & & & AP & EST & & & AP & EST & & & AP & EST & & \\
\hline J an & 1609 & 2068 & 8,12 & $7^{6}$ & 2684 & 3145 & 2,95 & $11^{6}$ & 1558 & 1345 & 1,86 & $12^{6}$ & 1215 & 1169 & 0,14 & $11^{6}$ \\
\hline Fev & 2429 & 1927 & 4,27 & $4^{7}$ & 1669 & 1869 & 1,44 & $4^{7}$ & 1386 & 1104 & 4,16 & $15^{7}$ & 836 & 1155 & 14,57 & $7^{7}$ \\
\hline Mar & 1600 & 1980 & 5,63 & $11^{8}$ & 2115 & 2725 & 8,33 & $21^{8}$ & 961 & 1236 & 8,14 & $7^{8}$ & 1331 & 991 & 6,50 & $17^{8}$ \\
\hline $\mathrm{Abr}$ & 634 & 816 & 8,27 & & 1038 & 1177 & 1,80 & & 737 & 721 & 0,05 & & 888 & 660 & 6,61 & \\
\hline Mai & 199 & 221 & 1,18 & & 125 & 218 & 55,28 & & 522 & 265 & 24,13 & & 178 & 214 & 3,99 & \\
\hline J un & 0 & 0 & 0,00 & & 171 & 179 & 0,00 & & 140 & 135 & 0,00 & & 183 & 205 & 1,44 & \\
\hline Jul & 0 & 0 & 0,00 & & 0 & 0 & 0,00 & & 10 & 16 & 0,00 & & 22 & 10 & 30,62 & \\
\hline Ago & 129 & 147 & 1,85 & & 0 & 0 & 0,00 & & 80 & 67 & 2,83 & & 20 & 34 & 49,27 & \\
\hline Set & 291 & 505 & 53,71 & & 393 & 667 & 48,55 & & 341 & 510 & 24,51 & & 137 & 144 & 0,20 & \\
\hline Out & 1568 & 1340 & 2,12 & & 2043 & 1726 & 2,40 & & 1393 & 801 & 18,07 & & 683 & 572 & 2,62 & \\
\hline Nov & 1769 & 1449 & 3,28 & & 2323 & 1818 & 4,73 & & 621 & 1093 & 57,74 & & 479 & 671 & 15,93 & \\
\hline Dez & 2286 & 2256 & 0,02 & & 3406 & 2680 & 4,54 & & 1136 & 1328 & 2,87 & & 1140 & 1337 & 2,99 & \\
\hline Anual & 12516 & 12708 & 1,54 & & 15965 & 16221 & 1,60 & & 8884 & 8620 & 2,98 & & 7113 & 7162 & 0,69 & \\
\hline
\end{tabular}

1 Índice de erosividade da chuva ( $\mathrm{El}_{303}-\mathrm{MJ} \mathrm{mm} \mathrm{ha}^{-1} \mathrm{~h}^{-1} \mathrm{ano}^{-1} \mathrm{e} \mathrm{El}_{30 \mathrm{~m}}-\mathrm{MJ} \mathrm{mm} \mathrm{ha}^{-1} \mathrm{~h}^{-1}$ mês $\left.{ }^{-1}\right) ;{ }^{2}$ valor do $\mathrm{El}_{30}$ determinado a partir da análise de pluviogramas; ${ }^{3}$ valor do $\mathrm{El}_{30}$ estimado a partir do coeficiente de chuva (Eq. 11, 12, 13 e 14); ${ }^{4}$ erro relativo da estimativa (\%); ${ }^{5}$ erro relativo médio da estimativa (\%); ${ }^{6,7}{ }^{8}$ ERM considerando os 12 meses do ano, meses mais erosivos e meses menos erosivos, respectivamente

(Mazurana et al., 2009), Cuiabá-MT (Almeida et al., 2011), Cáceres (Almeida, 2009), Rondonópolis (Almeida, 2009) e Região Centro-Leste de Minas Gerais (Silva et al., 2010). No entanto, contrasta com os dados de Lages e de Campos Novos, SC, Teodoro Sampaio, SP e Quaraí e Rio Grande, RS observados respectivamente por Bertol (1993; 1994), Colodro et al. (2002) e Peñalva Bazzano et al. (2007, 2010), cujos modelos de melhor ajuste foram o linear e o de Dourados, MS, em trabalho desenvolvido por Arai et al. (2010), no qual o modelo que melhor se ajustou foi um linear com raiz quadrada.

Na Tabela 3 estão apresentados os valores de $\mathrm{EI}_{30}$ mensal e anual obtidos partir da análise dos dados pluviográficos e estimados pelas eqs. 11, 12, 13 e 14 com os respectivos erros das estimativas para cada uma das localidades estudadas. É possível verificar que os erros relativos (ER) anuais foram bem menores que os erros relativos mensais, sendo o maior ER observado para a estimativa do $\mathrm{EI}_{30}$ anual para o município de Poxoréo $(2,98 \%)$, enquanto nos demais municípios o ER foi inferior a $2 \%$, com destaque para o município de São José do Rio Claro, em que o ER é igual a 0,69 .

Com relação às estimativas do $\mathrm{EI}_{30}$ mensal, observa-se que os ER foram mais elevados, chegando a valores iguais 57,74\% para o mês novembro no município de Poxoréo; entretanto, fazendo-se um agrupamento dos meses mais erosivos e menos

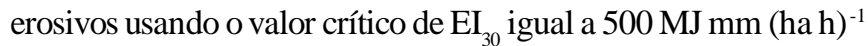
conforme proposto por Rufino (1986), é possível verificar que, com exceção de Poxoréo, os maiores ER ocorrem nos meses menos erosivos do ano, sendo que nos meses mais erosivos o erro relativo médio (ERM) é inferior a 7\%, com destaque para os municípios de Vera e canarana, nos quais o ERM foi de $4 \%$.

Sabendo-se que para o planjamento do uso de práticas de conservação do solo e da água é importante o conhecimento dos valores críticos, pode-se afirmar que as equações ajustadas para os municípios de Canarana, Vera e São José do Rio Claro podem ser utilizadas tanto para a estimativa da erosividade anual quanto para a estimativa da erosivade dos meses mais erosivos com boa confiabilidade.
Referidos resultados corroboram com os obtidos por vários pesquisadores que também encontraram correlações significativas entre o índice de erosividade $\mathrm{EI}_{30}$ e o Rc, as quais permitem estimar o valor de $\mathrm{EI}_{30}$ anual e mensal, dentre os mais recentes estão os resultados de Peñalva-Bazzano et al. (2007) que obtiveram correlação linear significativa $\left(\mathrm{EI}_{30}=-47,35+\right.$ 82,72 Rc) em Quaraí, RS; Almeida et al. (2011), que obtiveram relação potencial $\left(\mathrm{EI}_{30}=109,412 \mathrm{Rc}^{0,744}\right)$ com elevado coeficiente de determinação $\left(\mathrm{R}^{2}=0,91\right)$ em Cuiabá, MT, Almeida (2009), que obteve relação potencial $\left(\mathrm{EI}_{30 \text {-Rondonópolis }}=133,200429\right.$ $\mathrm{Rc}^{0,5372499} \mathrm{e} \mathrm{EI}_{30 \text {-Cáceres }}=172,632645 \mathrm{Rc}^{0,5245258}$ ) com elevados coeficientes de determinação $\left(\mathrm{R}^{2} \mathrm{e}\right.$ " 0,9$)$ para os municípios de Cáceres e Rondonópolis em Mato Grosso, mas isto contraria os resultados obtidos por Mazurana et al. (2009), que verificaram que a relação entre $\mathrm{EI}_{30}$ e Rc só deve ser utilizada para estimar o EI $\mathrm{I}_{30}$ anual para a região de Santa Rosa, RS, tendo em vista que tanto na relação linear $\left(\mathrm{EI}_{30}=354,71+44,927 \mathrm{Rc}\right)$ quanto na relação potencial $\left(\mathrm{EI}_{30}=118,52 \mathrm{Rc}^{0,8034}\right)$ entre o índice $\mathrm{EI}_{30 \mathrm{~m}} \mathrm{e}$ $\mathrm{Rc}_{\mathrm{m}}$, foram observados baixos coeficientes de regressão.

Na Tabela 4 são apresentados os valores médios mensais e anuais do índice de erosividade da chuva $\left(\mathrm{EI}_{30}\right)$ obtidos a partir da série histórica de dados pluviométricos dos municípios de Canarana (1986 a 2009), Vera (1975 a 2007), Poxoréo (1977 a 2007) e São José do Rio Claro (1991 a 2007), no Estado de Mato Grosso.

Os meses de janeiro e dezembro são, em média, os mais erosivos para Canarana, Poxoréo e São José do Rio Claro e também os responsáveis por 37, 38 e $31 \%$ da erosividade total anual, respectivamente. Em Vera, no entanto, fevereiro e dezembro foram os meses mais erosivos correspondendo a $34 \%$ da erosividade anual cujos resultados não corroboram com aqueles obtidos por Morais et al. (1991) para a região sudoeste do estado de Mato Grosso, os quais detectaram que os meses mais chuvosos foram janeiro e fevereiro ocorrendo, nesses meses, É ISTO? em média, 33\% do total anual precipitado e $43 \%$ da erosividade total anual embora corroborem com Arai et al. (2010), que encontraram as maiores erosividades da chuva 
Tabela 4. Parâmetros estatísticos (média, valor máximo, valor mínimo, desvio padrão, erro padrão médio e coeficiente de variação) do índice de erosividade mensal $\left(E_{30 m}-M J ~ m m ~ h a^{-1} h^{-1} m^{-1} s^{-1}\right)$ e anual $\left(E_{30}-M J ~ m m ~ h a-1 h^{-1} a^{-1}\right)$ obtidos a partir da série histórica de dados pluviométricos dos municípios de Canarana (1986 a 2009), Vera (1975 a 2007), Poxoréo (1977 a 2007) e São José do Rio Claro (1991 a 2007)

\begin{tabular}{|c|c|c|c|c|c|c|c|c|c|c|c|c|c|}
\hline Parâmetros & Jan & Fev & Mar & $A b r$ & Mai & Jun & Jul & Ago & Set & Out & Nov & Dez & Anual \\
\hline $\begin{array}{l}\mathrm{Md}^{1} \\
\mathrm{Mx}^{2} \\
\mathrm{Mn}^{3} \\
\mathrm{DP}^{4} \\
\mathrm{EPM}^{5} \\
\mathrm{CV}^{5}{ }^{6} \\
\end{array}$ & $\begin{array}{r}2288 \\
5869 \\
289 \\
1100 \\
220 \\
48,06 \\
\end{array}$ & $\begin{array}{r}2027 \\
3870 \\
0 \\
891 \\
178 \\
43,93 \\
\end{array}$ & $\begin{array}{r}1755 \\
3608 \\
0 \\
773 \\
155 \\
44,07 \\
\end{array}$ & $\begin{array}{r}778 \\
1772 \\
0 \\
455 \\
91 \\
58,53 \\
\end{array}$ & $\begin{array}{r}177 \\
564 \\
0 \\
178 \\
36 \\
100,77 \\
\end{array}$ & $\begin{array}{c}\text { Canarar } \\
38 \\
304 \\
0 \\
91 \\
18 \\
236,40 \\
\end{array}$ & $\begin{array}{r}7 \\
100 \\
0 \\
23 \\
5 \\
338,46 \\
\end{array}$ & $\begin{array}{r}33 \\
294 \\
0 \\
70 \\
14 \\
208,49 \\
\end{array}$ & $\begin{array}{r}270 \\
842 \\
0 \\
237 \\
47 \\
87,87 \\
\end{array}$ & $\begin{array}{r}1033 \\
2313 \\
0 \\
517 \\
103 \\
50,09 \\
\end{array}$ & $\begin{array}{r}1358 \\
2600 \\
0 \\
583 \\
117 \\
42,96 \\
\end{array}$ & $\begin{array}{r}2110 \\
3932 \\
0 \\
961 \\
192 \\
45,54 \\
\end{array}$ & $\begin{array}{r}11874 \\
14554 \\
7838 \\
1443 \\
289 \\
12,15 \\
\end{array}$ \\
\hline $\begin{array}{l}M d \\
M x \\
M n \\
D P \\
E P M \\
C V \% \\
\end{array}$ & $\begin{array}{r}2454 \\
3705 \\
977 \\
590 \\
103 \\
24,06 \\
\end{array}$ & $\begin{array}{r}2587 \\
4508 \\
1424 \\
750 \\
131 \\
29,00 \\
\end{array}$ & $\begin{array}{r}2156 \\
3842 \\
714 \\
779 \\
136 \\
36,13 \\
\end{array}$ & $\begin{array}{r}1102 \\
2037 \\
293 \\
468 \\
81 \\
42,41 \\
\end{array}$ & $\begin{array}{r}294 \\
871 \\
0 \\
246 \\
43 \\
83,73 \\
\end{array}$ & $\begin{array}{c}\text { Vera } \\
73 \\
757 \\
0 \\
168 \\
29 \\
229,47 \\
\end{array}$ & $\begin{array}{r}42 \\
377 \\
0 \\
89 \\
16 \\
213,74 \\
\end{array}$ & $\begin{array}{r}95 \\
551 \\
0 \\
155 \\
27 \\
163,29 \\
\end{array}$ & $\begin{array}{r}542 \\
1130 \\
0 \\
354 \\
62 \\
65,40 \\
\end{array}$ & $\begin{array}{r}1447 \\
2101 \\
588 \\
400 \\
70 \\
27,66 \\
\end{array}$ & $\begin{array}{r}2005 \\
4146 \\
675 \\
766 \\
133 \\
38,23 \\
\end{array}$ & $\begin{array}{r}2617 \\
4306 \\
1386 \\
612 \\
107 \\
23,40 \\
\end{array}$ & $\begin{array}{c}15414 \\
17087 \\
12984 \\
1017 \\
177 \\
6,60 \\
\end{array}$ \\
\hline $\begin{array}{l}M d \\
M x \\
M n \\
D P \\
\text { EPM } \\
C V \% \\
\end{array}$ & $\begin{array}{r}1397 \\
2135 \\
749 \\
360 \\
64 \\
25,77 \\
\end{array}$ & $\begin{array}{r}1228 \\
2107 \\
0 \\
412 \\
73 \\
33,54 \\
\end{array}$ & $\begin{array}{r}1145 \\
1840 \\
0 \\
495 \\
88 \\
43,26 \\
\end{array}$ & $\begin{array}{r}662 \\
1104 \\
0 \\
227 \\
40 \\
34,38 \\
\end{array}$ & $\begin{array}{r}308 \\
585 \\
0 \\
173 \\
31 \\
56,13 \\
\end{array}$ & $\begin{array}{c}\text { Poxoré } \\
113 \\
555 \\
0 \\
158 \\
28 \\
139,34 \\
\end{array}$ & $\begin{array}{r}50 \\
287 \\
0 \\
75 \\
13 \\
149,61 \\
\end{array}$ & $\begin{array}{r}107 \\
571 \\
0 \\
160 \\
28 \\
149,21 \\
\end{array}$ & $\begin{array}{r}456 \\
1245 \\
0 \\
314 \\
55 \\
68,77 \\
\end{array}$ & $\begin{array}{r}807 \\
1882 \\
0 \\
404 \\
71 \\
50,05 \\
\end{array}$ & $\begin{array}{r}1047 \\
1721 \\
0 \\
380 \\
67 \\
36,32 \\
\end{array}$ & $\begin{array}{r}1301 \\
2473 \\
0 \\
489 \\
87 \\
37,63 \\
\end{array}$ & $\begin{array}{r}8621 \\
10265 \\
5587 \\
969 \\
171 \\
11,24 \\
\end{array}$ \\
\hline $\begin{array}{c}M d \\
M x \\
M n \\
D P \\
\text { EPM } \\
\text { CV\% }\end{array}$ & $\begin{array}{r}1336 \\
2499 \\
219 \\
609 \\
148 \\
45,60\end{array}$ & $\begin{array}{r}1061 \\
2435 \\
0 \\
625 \\
152 \\
58,90\end{array}$ & $\begin{array}{r}999 \\
1752 \\
151 \\
436 \\
106 \\
43,62\end{array}$ & $\begin{array}{r}418 \\
1025 \\
94 \\
270 \\
66 \\
64,55\end{array}$ & $\begin{array}{c}\text { São } \\
142 \\
618 \\
0 \\
167 \\
40 \\
117,15\end{array}$ & $\begin{array}{c}\text { J osé do } \\
62 \\
452 \\
0 \\
134 \\
32 \\
214,71\end{array}$ & $\begin{array}{c}\text { o Claro } \\
16 \\
84 \\
0 \\
27 \\
6 \\
162,74\end{array}$ & $\begin{array}{c}15 \\
91 \\
0 \\
30 \\
7 \\
198,15\end{array}$ & $\begin{array}{r}154 \\
521 \\
0 \\
133 \\
32 \\
86,43\end{array}$ & $\begin{array}{r}542 \\
1280 \\
0 \\
322 \\
78 \\
59,45\end{array}$ & $\begin{array}{r}820 \\
2271 \\
0 \\
537 \\
130 \\
65,56\end{array}$ & $\begin{array}{r}1262 \\
2251 \\
260 \\
542 \\
132 \\
42,99\end{array}$ & $\begin{array}{r}6827 \\
7976 \\
3666 \\
967 \\
234 \\
14,16\end{array}$ \\
\hline
\end{tabular}

${ }^{1}$ média; ${ }^{2}$ valor máximo, ${ }^{3}$ valor mínimo; ${ }^{4}$ desvio padrão; ${ }^{5}$ erro padrão médio; ${ }^{6}$ coeficiente de variação

nos meses de janeiro e dezembro para a região de Dourados, MS, e corroboram também com os resultados encontrados por Almeida (2009), observando que janeiro e dezembro são, em média, os meses mais erosivos para Cáceres e Rondonópolis.

Considerando o valor crítico de $500 \mathrm{MJ} \mathrm{mm} \mathrm{ha}^{-1} \mathrm{~h}^{-1} \mathrm{mês}^{-1}$ (Rufino, 1986), pode-se observar que para os municípios de Canarana e Poxoréo o período de maior erosividade é semelhante, correspondente aos meses de outubro a abril, sendo responsável por 96 e $88 \%$ da erosividade da chuva anual, respectivamente. No entanto, o período de maior erosividade para os municípios Vera e São José do Rio Claro são diferentes entre si e dos dois anteriores, sendo que este período, para o primeiro município, compreende aos meses de setembro a abril, correspondendo a $97 \%$ da erosividade anual, enquanto para São José do Rio Claro os meses de outubro a março correspondem ao período de maior erosividade, sendo responsável por $94 \%$ do total anual. Desta forma verifica-se, então, que dentre as localidades estudadas, Poxoréo é aquela em que a erosividade é menos concentrada no período chuvoso.

Nas Tabelas 5 e 6 se encontram o período de retorno, a probabilidade de ocorrência e o mês mais crítico dos valores dos índices de erosividade observados para os municípios de Canarana, Vera, Poxoréo e São José do Rio Claro, considerandose o período das série de dados pluviométricos. Verifica-se que os meses de novembro, dezembro, janeiro e fevereiro foram aqueles mais erosivos em pelo menos $10 \%$ dos anos analisados para Vera e São José do Rio Claro, enquanto para Canarana e Poxoréo os meses que se apresentaram mais erosivos em mais de $10 \%$ dos anos analisados foram dezembro, janeiro e fevereiro. Esses meses de pico excepcional na erosividade das chuvas, são responsáveis por grandes danos nas lavouras cultivadas, pela ocorrência do processo de erosão hídrica (Mazurana et al., 2009).

Apesar de haver certa similaridade da variabilidade do regime pluviométrico ao longo do ano para as quatro localidades estudadas, principalmente para Canarana, Vera e São José do Rio Claro (96, 97 e 94\%, respectivamente), quantitativamente os valores de erosividade mensais e anuais são bem distintos, fato que pode ser evidenciado pelos valores do fator $\mathrm{R}$ obtidos para os municípios de Canarana, Vera Poxoréo e São José do Rio Claro, determinados através do índice de erosividade $\mathrm{EI}_{30}$, que foram de 11.874, 15.414, 8.621 e 6.827 $\mathrm{MJ} \mathrm{mm} \mathrm{ha}^{-1} \mathrm{~h}^{-1} \mathrm{ano}^{-1}$, respectivamente (Tabelas 5 e 6 ).

Pode-se verificar também que os anos mais erosivos são diferentes para todas as localidades, ou seja, a distribuição da erosividade da chuva ao longo dos anos também são bem distintos entre as localidades estudadas (Tabelas 5 e 6).

Os valores médios do fator $\mathrm{R}$ obtidos no presente trabalho se encontram dentro da faixa de variação de 3.116 a $20.035 \mathrm{MJ}$ $\mathrm{mm} \mathrm{ha}^{-1} \mathrm{~h}^{-1}$ ano $^{-1}$, observada por Silva (2004) na obtenção do mapa de erosividade da chuva para o Brasil. No entanto, pela 
Tabela 5. Probabilidade de ocorrência e período de retorno dos valores dos índices anuais de erosividade $\left(\mathrm{El}_{\text {30anual }} \mathrm{MJ}\right.$ $\mathrm{mm} \mathrm{ha-1} \mathrm{h}^{-1}$ ano-1) e mês de ocorrência da chuva mais erosiva do ano baseado na série histórica de dados pluviométricos dos municípios Canarana (1986 a 2009) e São José do Rio Claro (1991 a 2007)

\begin{tabular}{|c|c|c|c|c|c|c|c|c|c|c|c|c|c|}
\hline \multicolumn{7}{|c|}{ Canarana } & \multicolumn{7}{|c|}{ São J osé do Rio Claro } \\
\hline \multirow[t]{2}{*}{ Ano } & \multirow[t]{2}{*}{ El $_{30 \text { anual }}{ }^{1}$} & \multirow[t]{2}{*}{$\mathbf{m}^{2}$} & \multirow[t]{2}{*}{$T^{3}$} & \multirow[t]{2}{*}{$\mathbf{P}^{4}$} & \multicolumn{2}{|c|}{$\begin{array}{l}\text { Mês de ocorrência da chuva } \\
\text { mais erosiva do ano }\end{array}$} & \multirow[t]{2}{*}{ Ano } & \multirow[t]{2}{*}{$\mathrm{El}_{30 \text { anual }}{ }^{1}$} & \multirow[t]{2}{*}{$\mathbf{m}^{2}$} & \multirow[t]{2}{*}{$T^{3}$} & \multirow[t]{2}{*}{$\mathbf{P}^{4}$} & \multicolumn{2}{|c|}{$\begin{array}{l}\text { Mês de ocorrência da chuva } \\
\text { mais erosiva do ano }\end{array}$} \\
\hline & & & & & Mês & $\mathrm{El}_{30 \text { mensal }} 5$ & & & & & & Mês & $\mathrm{El}_{30 \text { mensal }}{ }^{5}$ \\
\hline 2004 & 14554 & 1 & 26,00 & 3,85 & J an & 5869 & 1992 & 7976 & 1 & 18,00 & 5,56 & Dez & 1999 \\
\hline 2005 & 14169 & 2 & 13,00 & 7,69 & Dez & 3932 & 2002 & 7917 & 2 & 9,00 & 11,11 & Jan & 1831 \\
\hline 1994 & 13285 & 3 & 8,67 & 11,54 & Mar & 3147 & 2006 & 7534 & 3 & 6,00 & 16,67 & Jan & 1759 \\
\hline 2006 & 12854 & 4 & 6,50 & 15,38 & Dez & 2496 & 1995 & 7359 & 4 & 4,50 & 22,22 & Dez & 2251 \\
\hline 1992 & 12828 & 5 & 5,20 & 19,23 & Dez & 2771 & 2005 & 7354 & 5 & 3,60 & 27,78 & Jan & 2499 \\
\hline 1997 & 12758 & 6 & 4,33 & 23,08 & Mar & 3608 & 2001 & 7259 & 6 & 3,00 & 33,33 & Jan & 1389 \\
\hline 2000 & 12715 & 7 & 3,71 & 26,92 & J an & 2610 & 1991 & 7028 & 7 & 2,57 & 38,89 & Mar & 1752 \\
\hline 1995 & 12678 & 8 & 3,25 & 30,77 & Jan & 3284 & 1994 & 6993 & 8 & 2,25 & 44,44 & Jan & 1419 \\
\hline 1991 & 12440 & 9 & 2,89 & 34,62 & Jan & 3345 & 2000 & 6862 & 9 & 2,00 & 50,00 & Dez & 2126 \\
\hline 1985 & 12422 & 10 & 2,60 & 38,46 & Jan & 3362 & 2004 & 6849 & 10 & 1,80 & 55,56 & Fev & 2435 \\
\hline 2002 & 12398 & 11 & 2,36 & 42,31 & Fev & 2828 & 1996 & 6798 & 11 & 1,64 & 61,11 & J an & 1253 \\
\hline 1993 & 12343 & 12 & 2,17 & 46,15 & Fev & 3870 & 2007 & 6776 & 12 & 1,50 & 66,67 & Nov & 1262 \\
\hline 1996 & 12154 & 13 & 2,00 & 50,00 & J an & 2422 & 2003 & 6716 & 13 & 1,38 & 72,22 & J an & 2094 \\
\hline 1988 & 12088 & 14 & 1,86 & 53,85 & Mar & 2655 & 1993 & 6651 & 14 & 1,29 & 77,78 & Nov & 1234 \\
\hline 2001 & 11815 & 15 & 1,73 & 57,69 & J an & 2427 & 1997 & 6485 & 15 & 1,20 & 83,33 & J an & 1651 \\
\hline 2003 & 11745 & 16 & 1,63 & 61,54 & Fev & 2913 & 1999 & 5845 & 16 & 1,13 & 88,89 & Nov & 2271 \\
\hline 1999 & 11473 & 17 & 1,53 & 65,38 & Fev & 2958 & 1998 & 3666 & 17 & 1,06 & 94,44 & Fev & 2308 \\
\hline 2007 & 11191 & 18 & 1,44 & 69,23 & Fev & 2824 & $\mathrm{Md}^{6}$ & 6827 & - & - & - & - & - \\
\hline 1990 & 10991 & 19 & 1,37 & 73,08 & fev & 3481 & $M x^{7}$ & 7976 & - & - & - & - & - \\
\hline 1987 & 10932 & 20 & 1,30 & 76,92 & Dez & 3241 & $\mathrm{DP}^{8}$ & 966,53 & - & - & - & - & - \\
\hline 1986 & 10902 & 21 & 1,24 & 80,77 & Dez & 3116 & EPM $^{9}$ & 193,31 & - & - & - & - & - \\
\hline 2009 & 10606 & 22 & 1,18 & 84,62 & Dez & 3302 & $\mathrm{CV}^{10}$ & 14,16 & - & - & - & - & - \\
\hline 1998 & 10476 & 23 & 1,13 & 88,46 & Fev & 2149 & & & & & & & \\
\hline 2008 & 9199 & 24 & 1,08 & 92,31 & J an & 3312 & & & & & & & \\
\hline 1989 & 7838 & 25 & 1,04 & 96,15 & Fev & 2782 & & & & & & & \\
\hline$M d^{6}$ & 11874 & - & & & - & & & & & & & & \\
\hline$M x^{7}$ & 14554 & - & - & - & - & - & & & & & & & \\
\hline $\mathrm{DP}^{8}$ & 1442,74 & - & - & - & - & . & & & & & & & \\
\hline $\mathrm{EPM}^{9}$ & 288,55 & - & - & - & - & - & & & & & & & \\
\hline $\mathrm{CV}^{10}$ & 12,15 & - & - & - & - & - & & & & & & & \\
\hline
\end{tabular}

${ }^{1}$ Índice de erosividade anual em MJ mm ha ${ }^{-1}$ (ano $\left.\mathrm{h}\right)^{-1} ;{ }^{2}$ Número da ordem; ${ }^{3}$ Período de retorno; ${ }^{4}$ Probabilidade de ocorrência; ${ }^{5}$ Índice de erosividade mensal em $\mathrm{MJ}$ mm ha ${ }^{-1} \mathrm{~h}^{-1} ;{ }^{6}$ média; ${ }^{7}$ máximo; 8 desvio padrão; ${ }^{9}$ erro padrão médio; ${ }^{10}$ coeficiente de variação, $\%$

faixa estabelecida para o País de 5.000 a $12.000 \mathrm{MJ} \mathrm{mm} \mathrm{ha}^{-1} \mathrm{~h}^{-1}$ $\mathrm{ano}^{-1}$, apenas Vera apresentou fator $\mathrm{R}$ fora desta faixa, sendo que Canarana, Poxoréo e São José do Rio Claro o fator R ficaram próximas do limite superior, metade e próximo ao limite inferior desta faixa, respectivamente. Considerando a classificação da erosividade baseada no fator R (Foster et al., 1981), os municípios de Canarana e Vera podem ser classificados como de erosividade muito alta, Poxoréo de erosividade alta e São José do Rio Claro de erosividade de média a alta.

Nas localidades estudadas no presente trabalho as práticas de preparo do solo e plantio das áreas agrícolas são coincidentes com o período de ocorrência das chuvas mais erosivas e com o solo mais exposto e alta erosividade das chuvas, os cuidados no controle da erosão deverão ser ainda maiores, mas os picos mensais mais notáveis da erosividade das chuvas, principalmente nos municípios de Canarana e Poxoréo, ocorrem nos meses em que, normalmente, as culturas de verão estão em pleno desenvolvimento, mantendo o solo quase que totalmente coberto reduzindo, desta forma, os danos causados pelo potencial erosivo das chuvas.

A função de Gumbel simplificada por Ven Te Chow (Figura 1), típica de eventos extremos de precipitação (Pinto et al.,

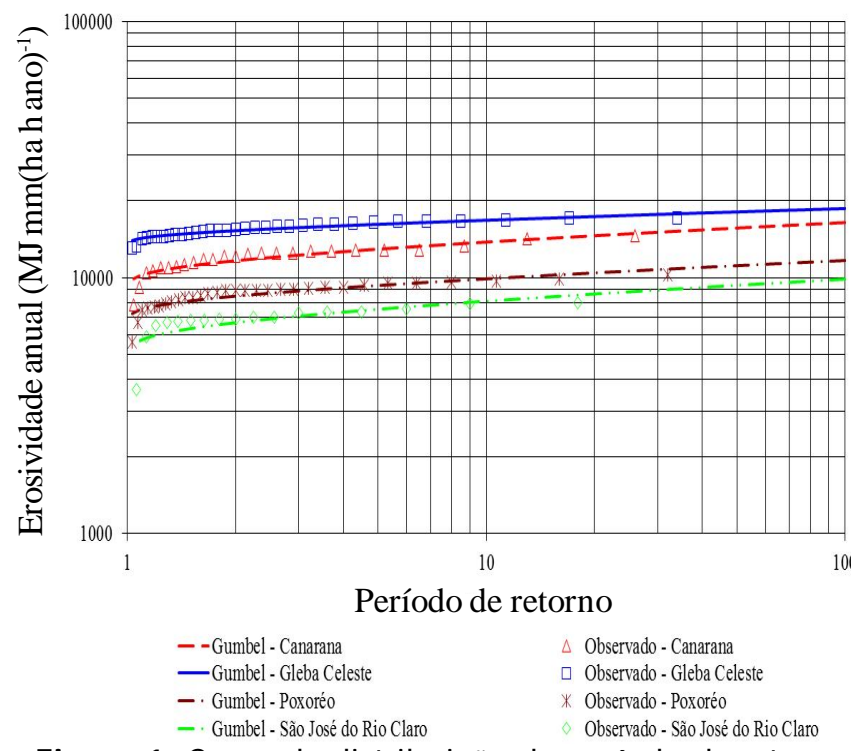

Figura 1. Curva de distribuição do período de retorno dos índices anuais de erosividade da chuva baseado na série histórica de dados pluviométricos dos municípios de Canarana (1986 a 2009), Vera (1975 a 2007), Poxoréo (1977 a 2007) e São José do Rio Claro (1991 a 2007) 
Tabela 6. Probabilidade de ocorrência e período de retorno dos valores dos índices anuais de erosividade (El ${ }_{30 a n u a l '}$ MJ mm ha- ${ }^{-1} \mathrm{~h}^{-1} \mathrm{ano}^{-1}$ ) e mês de ocorrência da chuva mais erosiva do ano baseado na série histórica de dados pluviométricos dos municípios de Poxoréo (1977 a 2007) e Vera (1975 a 2007)

\begin{tabular}{|c|c|c|c|c|c|c|c|c|c|c|c|c|c|}
\hline \multicolumn{7}{|c|}{ Poxoréo } & \multicolumn{7}{|c|}{ Vera } \\
\hline \multirow[t]{2}{*}{ Ano } & \multirow[t]{2}{*}{$\mathrm{El}_{30 \text { anual }}{ }^{1}$} & \multirow[t]{2}{*}{$\mathrm{m}^{2}$} & \multirow[t]{2}{*}{$T^{3}$} & \multirow[t]{2}{*}{$\mathbf{P}^{4}$} & \multicolumn{2}{|c|}{$\begin{array}{c}\text { Mês de ocorrência da chuva } \\
\text { mais erosiva do ano }\end{array}$} & \multirow[t]{2}{*}{ Ano } & \multirow[t]{2}{*}{$\mathrm{El}_{30 \text { anual }}{ }^{1}$} & \multirow[t]{2}{*}{$\mathrm{m}^{2}$} & \multirow[t]{2}{*}{$\mathrm{T}^{3}$} & \multirow[t]{2}{*}{$\mathbf{P}^{4}$} & \multicolumn{2}{|c|}{$\begin{array}{l}\text { Mês de ocorrência da chuva } \\
\text { mais erosiva do ano }\end{array}$} \\
\hline & & & & & Mês & $\mathrm{El}_{30 \text { mensal }}{ }^{5}$ & & & & & & Mês & $\mathrm{El}_{30 \text { mensal }}{ }^{5}$ \\
\hline 1980 & 10265 & 1 & 32,00 & 3,13 & Jan & 1918 & 1978 & 17087 & 1 & 34,00 & 2,94 & Dez & 3453 \\
\hline 2001 & 9868 & 2 & 16,00 & 6,25 & Dez & 2473 & 1980 & 16999 & 2 & 17,00 & 5,88 & Jan & 3405 \\
\hline 1986 & 9689 & 3 & 10,67 & 9,38 & Dez & 1784 & 1994 & 16807 & 3 & 11,33 & 8,82 & Jan & 3470 \\
\hline 1983 & 9561 & 4 & 8,00 & 12,50 & Jan & 1379 & 1985 & 16645 & 4 & 8,50 & 11,76 & Jan & 3433 \\
\hline 1981 & 9539 & 5 & 6,40 & 15,63 & $\mathrm{Fev}$ & 1769 & 1982 & 16572 & 5 & 6,80 & 14,71 & Mar & 2792 \\
\hline 1978 & 9473 & 6 & 5,33 & 18,75 & Dez & 1681 & 1989 & 16560 & 6 & 5,67 & $\begin{array}{l}17,11 \\
17,65\end{array}$ & Dez & 4306 \\
\hline 1982 & 9297 & 7 & 4,57 & 21,88 & Jan & 1720 & 1976 & 16451 & 7 & 4,86 & 20,59 & Fev & 3713 \\
\hline 2003 & 9190 & 8 & 4,00 & 25,00 & Mar & 1840 & 2006 & 16316 & 8 & 4,25 & 23,53 & Dez & 3337 \\
\hline 2006 & 9152 & 9 & 3,56 & 28,13 & Mar & 1821 & 1995 & 16158 & 9 & 3,78 & 26,47 & Jan & 3025 \\
\hline 1987 & 9111 & 10 & 3,20 & 31,25 & Dez & 2030 & 1992 & 16122 & 10 & 3,40 & 29,41 & Dez & 3092 \\
\hline 2002 & 9020 & 11 & 2,91 & 34,38 & Nov & 1717 & 1986 & 15974 & 11 & 3,09 & 32,35 & Fev & 3510 \\
\hline 1997 & 9010 & 12 & 2,67 & 37,50 & Jan & 1934 & 1981 & 15801 & 12 & 2,83 & 35,29 & Mar & 3842 \\
\hline 1994 & 8947 & 13 & 2,46 & 40,63 & Nov & 1721 & 1991 & 15796 & 13 & 2,62 & 38,24 & Jan & 3705 \\
\hline 1977 & 8920 & 14 & 2,29 & 43,75 & Fev & 1365 & 2003 & 15703 & 14 & 2,43 & 41,18 & Jan & 2705 \\
\hline 1992 & 8905 & 15 & 2,13 & 46,88 & Out & 1882 & 1999 & 15648 & 15 & 2,27 & 44,12 & Dez & 3472 \\
\hline 1991 & 8892 & 16 & 2,00 & 50,00 & Jan & 1549 & 1996 & 15545 & 16 & 2,13 & 47,06 & Nov & 2753 \\
\hline 1979 & 8877 & 17 & 1,88 & 53,13 & Jan & 2047 & 1977 & 15469 & 17 & 2,00 & 50,00 & Nov & 3130 \\
\hline 1998 & 8780 & 18 & 1,78 & 56,25 & Fev & 1784 & 1988 & 15307 & 18 & 1,89 & 52,94 & Fev & 3282 \\
\hline 1996 & 8692 & 19 & 1,68 & 59,38 & Jan & 1453 & 1983 & 15290 & 19 & 1,79 & 55,88 & Mar & 3230 \\
\hline 2004 & 8528 & 20 & 1,60 & 62,50 & Jan & 1889 & 2004 & 15244 & 20 & 1,70 & 58,82 & Fev & 3405 \\
\hline 1990 & 8350 & 21 & 1,52 & 65,63 & Dez & 1367 & 2000 & 15063 & 21 & 1,62 & 61,76 & Fev & 3561 \\
\hline 2005 & 8310 & 22 & 1,45 & 68,75 & Mar & 1640 & 2007 & 15033 & 22 & 1,55 & 64,71 & Fev & 4508 \\
\hline 2000 & 8228 & 23 & 1,39 & 71,88 & Fev & 1800 & 1987 & 14849 & 23 & 1,48 & 67,65 & Fev & 2986 \\
\hline 1995 & 8018 & 24 & 1,33 & 75,00 & Dez & 1557 & 1990 & 14712 & 24 & 1,42 & 70,59 & Fev & 3207 \\
\hline 1993 & 7907 & 25 & 1,28 & 78,13 & Dez & 1897 & 1984 & 14706 & 25 & 1,36 & 73,53 & Fev & 2822 \\
\hline 1989 & 7760 & 26 & 1,23 & 81,25 & Jan & 2135 & 2005 & 14583 & 26 & 1,31 & 76,47 & Mar & 3816 \\
\hline 1988 & 7667 & 27 & 1,19 & 84,38 & $\mathrm{Fev}$ & 2107 & 1997 & 14498 & 27 & 1,26 & 79,41 & Dez & 3166 \\
\hline 1984 & 7594 & 28 & 1,14 & 87,50 & Dez & 1551 & 1975 & 14483 & 28 & 1,21 & 82,35 & Fev & 2909 \\
\hline 2007 & 7449 & 29 & 1,10 & 90,63 & Nov & 1321 & 1993 & 14472 & 29 & 1,17 & 85,29 & Nov & 2692 \\
\hline 1985 & 6679 & 30 & 1,07 & 93,75 & Dez & 1435 & 1998 & 14296 & 30 & 1,13 & 88,24 & Nov & 4146 \\
\hline 1999 & 5587 & 31 & 1,03 & 96,88 & Dez & 1629 & 2001 & 14163 & 31 & 1,10 & 91,18 & Fev & 3119 \\
\hline$M d^{6}$ & 8621 & - & - & - & - & - & 2002 & 13335 & 32 & 1,06 & 94,12 & Jan & 2692 \\
\hline$M x^{7}$ & 10265 & - & - & - & - & - & 1979 & 12984 & 33 & 1,03 & 97,06 & $\mathrm{Fev}$ & 2766 \\
\hline $\mathrm{DP}^{8}$ & 969,08 & - & - & - & - & - & $M d^{6}$ & 15414 & - & - & - & - & - \\
\hline $\mathrm{EPM}^{9}$ & 193,82 & - & - & - & - & - & $M x^{7}$ & 17087 & - & - & - & - & - \\
\hline \multirow[t]{3}{*}{$\mathrm{CV}^{10}$} & 11,24 & - & - & - & - & - & $\mathrm{DP}^{8}$ & 1016,98 & - & - & - & - & - \\
\hline & & & & & & & $\mathrm{EPM}^{9}$ & 177,03 & - & - & - & - & - \\
\hline & & & & & & & $\mathrm{CV}^{10}$ & 6,60 & - & - & - & - & - \\
\hline
\end{tabular}

1 Índice de erosividade anual em MJ mm ha-1 (ano h)-1-1 ${ }^{2}$ Número da ordem; ${ }^{3}$ Período de retorno; ${ }^{4}$ Probabilidade de ocorrência; ${ }^{5}$ Índice de erosividade mensal em $\mathrm{MJ}^{\mathrm{mm}}$ ha ${ }^{-1} \mathrm{~h}^{-1} ;{ }^{6}$ média; ${ }^{7}$ desvio padrão; ${ }^{8}$ máximo; ${ }^{9}$ erro padrão médio; ${ }^{10}$ coeficiente de variação, $\%$

1996), ajustou-se bem aos dados para descrever as curvas de distribuição de probabilidade dos valores de erosividade anual para os quatro municípios, corroborando com resultados obtidos por outros pesquisadores como, por exemplo, Carvalho et al. (2010; 2004), Almeida (2009) e Almeida et al. (2011).

Aplicando esta função de probabilidade (Eq. 8) é possível verificar que o valor médio da erosividade anual do período considerado (que é o valor do Fator "R" da USLE) para os municípios de Canarana, Vera, Poxoréo e São José do Rio Claro, possui um período de retorno estimado de 2,33 anos com $43 \%$ de probabilidade de ocorrência para ambos os municípios.

Este período de retorno encontrado para o fator $\mathrm{R}$ dos municípios em estudo é semelhante àqueles obtidos para Campinas (2,1 anos), Botucatu (2,3 anos), Cáceres e Rondonópolis (2,33), Cuaibá (2,3), Santa Rosa (2,3) determinados por Lombardi Neto (1977), Carvalho et al. (2004),
Almeida (2009), Almeida et al. (2011) e Mazurana et al. (2009), respectivamente.

Cabe ressaltar que, embora se observe semelhança entre o período de retorno e a probabilidade de ocorrência do fator $\mathrm{R}$ obtidas no presente trabalho com as localidades supra citadas, $\mathrm{O}$ valor do fator $\mathrm{R}$ obtido neste trabalho distingue daqueles encontrados nos trabalhos citados anteriormente evidenciando, então, a grande importância de se realizar este tipo de caracterização para cada localidade e/ou região, sendo muito prováveis, erros ao se utilizar valores de outras regiões ou localidades.

\section{CONCLUsões}

1. A relação potencial entre o índice de erosividade da chuva e o coeficiente de chuva possibilita estimar o erosividade da 
chuva mensal e anual com boa confiabilidade (ERM d" 7\%) para os municípios de Canarana, Vera e São José do Rio Claro, enquanto em Poxoréo esta boa confiabilidade só é possível para a erosividade anual.

2. As localidades estudadas apresentam erosividades da chuva bastante distintas, sendo que Canarana e Vera possuem erosividade muito alta, Poxoréo alta e São José do Rio Claro de média a alta não sendo recomendado, desta forma, utilizar valores de $\mathrm{R}$ de um local para outro.

3. Para os quatro municípios estudados as estações primavera e verão correspondem ao período do ano de maior erosividade, ocorrendo neste período, à exceção de Poxoréo, uma proporção maior ou igual a $94 \%$ do valor da erosividade total anual, indicando que este período, para esses locais, deve ser aquele de maior preocupação com as perdas anuais de solo por erosão hídrica.

4. Dentre os municípios estudados Poxoréo é aquele em que a ocorre a menor proporção ( $88 \%$ ) da erosividade anual no período chuvoso (estações primavera e verão).

5. Os meses de dezembro, janeiro e fevereiro são os que se apresentaram com maior frequência como os mais erosivos do ano para Vera e São José do Rio Claro e novembro, dezembro, janeiro e fevereiro para os municípios de Canarana e Poxoréo.

\section{AgradeCIMENTOS}

Os autores agradecem à Fundação de Amparo à Pesquisa do Estado de Mato Grosso (FAPEMAT), pelo auxílio financeiro para desenvolvimento desta pesquisa; à Coordenação de Aperfeiçoamento de Pessoal de Nível Superior (CAPES) e ao Conselho Nacional de Desenvolvimento Científico e Tecnológico (CNPq), pela concessão da bolsa de estudo aos discentes envolvidos nesta pesquisa.

\section{LITERATURA CITADA}

Almeida, C. O. S. Erosividade das chuvas no Estado de Mato Grosso. Brasília: UnB, 2009. 83p. Dissertação Mestrado

Almeida, C. O. S.; Amorim, R. S. S.; Couto, E. G.; Eltz, F.L. F.; Borges, L.E.C. Potencial erosivo da chuva de Cuiabá (MT): Distribuição e correlação com a precipitação pluviométrica. Revista Brasileira Engenharia Agrícola e Ambiental, v.5, p.178-184, 2011.

Amorim, R. S. S.; Silva, D. D.; Pruski, F. F.; Matos, A. T. Avaliação dos modelos de predição da erosão hídrica USLE, RUSLE e WEPP para diferentes condições edafoclimáticas do Brasil. Engenharia Agrícola, v.30, p.1046-1059, 2010.

Arai, F. K.; Goncalves, G. G. G.; Pereira, S. B.; Comunello, E.; Vitorino, A. C. T.; Daniel, O. Espacialização da precipitação e erosividade na Bacia Hidrográfica do Rio Dourados, MS. Engenharia Agrícola, v.30, p.922-931, 2010.

Bertol, I. Índice de erosividade $\left(\mathrm{EI}_{30}\right)$ para Lages $(\mathrm{SC})-1^{\mathrm{a}}$. aproximação. Pesquisa Agropecuária Brasileira, v.28, p.515$521,1993$.
Bertol, I. Avaliação da erosividade da chuva na localidade de Campos Novos (SC) No período de 1981-1990. Pesquisa Agropecuária Brasileira, v.29, p.1453-1458, 1994.

Bertoni, J.; Lombardi Neto, F.; Benati Júnior, R. Equação de perdas de solo. Campinas: Instituto Agronômico de Campinas, 1975. 25p. Boletim Técnico, 21

Carvalho, D. F. de; Machado, R. L.; Evangelista, A. W. P.; Khoury Júnior, J. K.; Silva, L. D. B. da. Distribuição, probabilidade de ocorrência e período de retorno dos índices de erosividade EI30 e KE> 25 em Seropédica, RJ. Engenharia Agrícola, v.30, p.245-252, 2010.

Carvalho, M. P.; Lombardi Neto, F.; Vasques Filho, J.; Cataneo, A. İndices de erosividade da chuva correlacionada com as perdas de um Podzólico Vermelho-amarelo eutrófico textura argilosa/muito argilosa de Mococa (SP): Primeira aproximação do fator erodibilidade dos solos. Revista Brasileira Ciência do Solo, v.13 p.237-242, 1989.

Carvalho, M. P. E.; Freddi, O. S.; Veronese Júnior, V. Critérios para classificação de chuva individual erosiva para o Estado de São Paulo. Acta Scientiarum, v.26, p.175-183, 2004.

Colodro, G.; Carvalho, M. P.; Roque, C. G.; Prado, R. M. Erosividade da chuva: distribuição e correlação com a precipitação pluviométrica de Teodoro Sampaio (SP). Revista Brasileira Ciência do Solo, v.26, p.809-818, 2002.

Foster, G. R.; Mccool, D. K.; Renard, K. G.; Moldenhauer, W. C. Conversion of the universal soil loss equation to SI units. Journal of Soil and Water Conservation, v.36, p.355-359, 1981.

Gonçalves, F. A.; Silva, D. D.; Pruski, F. F.; Carvalho, D. F.; Cruz, E. S. Índices e espacialização da erosividade das chuvas para o Estado do Rio de Janeiro. Revista Brasileira Engenharia Agrícola e Ambiental, v.10, p. 269-276, 2006.

Hernani, L. C.; Freitas, P. L.; Pruski, F. F.; De Maria, I. C.; Castro Filho, C.; Landers, J. C. A erosão e seu impacto. In: Manzatto, C. V.; Freita Júnior, E.; Peres, J. R. R. Rio de Janeiro: Embrapa Solos, 2002. p.47-60.

Lombardi Neto, F. Rainfall erosivity - Its distribution and relationship with soil loss at Campinas, Brazil. West Lafayette: Purdue University, 1977. 53p. Dissertação Mestrado

Mazurana, J.; Cassol, E. A.; Santos, L. C. dos; Eltz, F. L. F.; Bueno, A. C. Erosividade, padrões hidrológicos e período de retorno das chuvas erosivas de Santa Rosa (RS). Revista Brasileira Engenharia Agrícola e Ambiental, v.13, p.975-983, 2009.

Mello, C. R.; Sá, M. A. C.; Curi, N.; Mello, J. M.; Viola, M. R. Erosividade mensal e anual da chuva no Estado de Minas Gerais. Pesquisa Agropecuária Brasileira, v.42, p.537-545, 2007.

Men, M.; Yu, Z.; Xu, H. Study on the spatial pattern of rainfall erosivity based on geostatistics in Hebei Province, China. Frontiers of Agriculture in China, v.2, p. 281-289, 2008.

Montebeller, C. A.; Ceddia, Carvalho, D. F.; Vieira, S. R.; Franco, E. M. Variabilidade espacial do potencial erosivo das chuvas no Estado do Rio de Janeiro. Engenharia Agrícola, v.27, p.426-435, 2007. 
Morais, L. F.B.; Silva, V.; Naschenveng, T. M. C.; Hardoin, P. C.; Almeida, J. E. L.; Weber, O. L. S.; Boel, E.; Durigon, V. Índice $\mathrm{EI}_{30}$ e sua relação com o coeficiente de chuva do sudoeste do Mato Grosso. Revista Brasileira Ciência do Solo, v.15, p.339-44, 1991.

Peñalva Bazzano, M. G. Coeficiente de chuva, padrões e período de retorno das chuvas de Quarai e Rio Grande, RS. Santa Maria: UFSM, 2005. 64p. Dissertação Mestrado

Peñalva Bazzano, M. G.; Eltz, F. L. F.; Cassol, E. A. Erosividade, coeficiente de chuva, padrões e período de retorno das chuvas de Quaraí, RS. Revista Brasileira Ciência do Solo, v.31, p.1205-1217, 2007.

Peñalva Bazzano, M. G.; Eltz, F. L. F.;Cassol, E. A. Erosividade e características hidrológicas das chuvas de Rio Grande (RS). Revista Brasileira Ciência do Solo, v.34, p.235-244, 2010.

Pinto, F. A.; Ferreira, P. A.; Pruski, F. F.; Alves, A. R.; Cecon, P. R. Estimativa de chuvas intensas no Estado de Minas Gerais utilizando registros diários. Engenharia Agrícola, v.16, p.821, 1996.
Rufino, R. L. Avaliação do potencial erosivo da chuva para o Estado do Paraná: segunda aproximação. Revista Brasileira Ciência do Solo, v.10, p.279-281, 1986.

Schwab, G. O.; Frevert, R. K.; Edminster, T. W.; Barnes, K. K. Soil and water conservation en gineering. 3.ed. New York: John Wiley \& Sons, 1981. 525p.

Silva, A. M. Rainfall erosivity map for Brazil. Catena, v.57, p.251259, 2004.

Silva, M. A.; Silva, M. L. N.; Curi, N.; Santos, G. R.; Marques, J. J. G. S. E. M.; Menezes, M. D.; Leite, F. P. Avaliação e espacialização da erosividade da chuva no Vale do Rio Doce, região Centro-Leste do Estado de Minas Gerais. Revista Brasileira Ciência doSolo, v.34, p.1029-1039, 2010.

Wischmeier, W. H.; Smith, D. D. Rainfall energy and its relationship to soil loss. Transaction American Geophysical Union, v.39, p.285-91, 1958.

Wischmeier, W. H.; Smith, D. D. Predicting rainfall erosion losses: A guide to conservation planning. Washington: USDA, 1978. 58p. Agriculture handbook 537 